\title{
COLHEITA DE CITROS E OBTENÇÃO DE DADOS PARA MAPEAMENTO DA PRODUTIVIDADE
}

\section{JOSÉ P. MOLIN ${ }^{1}$, LEONARDO S. MASCARIN ${ }^{2}$}

\begin{abstract}
RESUMO: A citricultura é de fundamental importância para a economia brasileira devido a sua expressiva participação na exportação e pela geração de empregos. A colheita manual é atualmente realizada na totalidade das propriedades citrícolas nacionais. A ausência de técnicas para a geração de mapas de produtividade em citros é uma das grandes dificuldades para a implantação da agricultura de precisão, o que justifica empreender técnicas e equipamentos para essa finalidade. Neste trabalho, teve-se o objetivo de ter o correto entendimento dos sistemas de colheita existentes, suas características úteis e limitações. A partir de então, desenvolveu-se e testou-se uma proposta de geração de dados para obtenção de mapas de produtividade sem interferir no processo vigente. Procedeu-se à pesagem de uma população de sacolões ("big bag") para aferir a informação de massa estimada pelo responsável pela colheita. Na seqüência, realizou-se o georreferenciamento de todos os sacolões de uma área. A partir da largura da faixa de colheita e do cálculo de distância entre os sacolões, obtiveram-se as áreas de contribuição de cada um, e com a massa estimada determinou-se a produtividade dos pontos. Esses dados foram interpolados gerando o mapa de produtividade. A estimativa de massa dos sacolões mostrou-se aceitável e o método válido para a coleta de dados e a geração do mapa de produtividade.
\end{abstract}

PALAVRAS-CHAVE: laranja, agricultura de precisão, mapa de produtividade.

\section{CHARACTERIZATION OF HARVEST SYSTEMS AND DEVELOPMENT YIELD MAPPING FOR CITRUS}

\begin{abstract}
Citriculture activity is important for the Brazilian economy due to its expressive participation on exporting and for the generation of a number of job positions. Manual harvesting is currently predominant. Routine generation of yield mapping for citrus is necessary for implementing precision agriculture practices, what justifies efforts for developing techniques for data collection. The objective of this research was to promote the correct understanding of the variations on harvesting systems, their useful characteristics and limitations, also propose and test a methodology for collecting data to attain yield maps without interfering in the process. A population of big bags was weighed checking the estimated weight by the manager responsible for the payment of the workers. Finally all the big bags of a field were georeferenced, allowing for the calculation of the representative individual area from the constant strip width and distance between bags. From the area and mass of each bag the productivity was determined and the yield map was generated after interpolating the data. The estimation of mass was considered acceptable and the method is considered simple and efficient for collection of data and generation of yield maps.
\end{abstract}

KEYWORDS: orange, precision agriculture, yield map.

\footnotetext{
${ }^{1}$ Eng $^{\mathrm{o}}$ Agrícola, Prof. Livre-Docente, Departamento de Engenharia Rural, ESALQ/USP, Piracicaba - SP, Fone: (0XX19) 3447 8502, jpmolin@esalq.usp.br

2 Eng ${ }^{\mathrm{o}}$ Agrônomo, Mestrando, Departamento de Engenharia Rural, ESALQ/USP, Piracicaba - SP, leomascarin@ yahoo.com.br. Recebido pelo Conselho Editorial em: 15-5-2006
}

Aprovado pelo Conselho Editorial em: 22-1-2007 


\section{INTRODUÇÃO}

A importância da citricultura para o Brasil está relacionada às exportações e à geração de empregos. De acordo com dados da FAO (2005), a produção mundial de laranja foi de 63 milhões de toneladas, tendo o Brasil a posição de líder, com produção de 18,2 milhões de toneladas, seguido pelos EUA, México, Índia e China. A área cultivada com laranjais no Brasil é de aproximadamente 820.267 ha distribuídos em 27 mil estabelecimentos rurais.

Embora já existam iniciativas para a colheita mecanizada e semimecanizada, a colheita manual é atualmente realizada na totalidade das propriedades citrícolas nacionais. É um processo que exige grande quantidade de mão-de-obra e apresenta diversificação entre as empresas para adaptar-se a necessidades internas.

Na implantação de práticas de agricultura de precisão em citros, a dificuldade está em gerar mapas de produtividade, justificando a pesquisa de técnicas e equipamentos para a geração dessa informação. Um dos primeiros trabalhos para o mapeamento da produtividade de laranja foi realizado por WHITNEY et al. (1998), seguido por HORROM (2000) e MILLER \& WHITNEY (1998). Os métodos mostraram-se adequados para as condições em que foram propostos, porém com limitações. No Brasil, BALASTREIRE et al. (2002), PARISE (2004) e FARIAS et al. (2003) também obtiveram mapas de produtividade utilizando técnicas diferenciadas e que exigiram adaptações e mudanças na prática da operação de colheita.

Este trabalho teve o objetivo de obter o correto entendimento da operação de colheita de citros, suas características úteis e limitações, e a partir de então desenvolver e testar uma proposta para a geração de dados para a obtenção de mapas de produtividade, com procedimentos simples e que respeitem as rotinas preexistentes no sistema predominante de colheita vigente.

\section{MATERIAL E MÉTODOS}

A ausência de textos referentes à caracterização detalhada do sistema de colheita e suas diferenciações entre empresas citrícolas nacionais geraram a necessidade desse detalhamento. Para ilustrar e caracterizar os sistemas utilizados, empresas foram contactadas e forneceram informações da operação.

Atualmente, a determinação de quantidade de frutos colhidos pelos colhedores, a fim de realizar o pagamento, é realizada pela técnica em que o responsável de colheita (apontador) utiliza uma régua graduada com valores de número de caixas de colheita para estimar, inicialmente, o volume. No entanto, no mercado, essa unidade (caixa) equivale ao peso de $27,2 \mathrm{~kg}$. Com o intuito de determinar o nível de confiabilidade da estimativa realizada pelo apontador, foi efetuada a pesagem de uma população de sacolões, na safra de 2005, na Fazenda Santa Isabel, localizada no município de Brotas - SP. Foram pesados os sacolões de duas equipes de colheita (1 e 2) com seus distintos apontadores. Obtiveram-se as massas $(\mathrm{kg})$ estimadas pelo apontador e os pesos reais obtidos com a pesagem. A população da pesagem consistiu do total de 65 sacolões em cada equipe de colheita.

Para realizar a pesagem dos sacolões, foi utilizada uma célula de carga modelo LU-2TE (Kyowa Eletronic Instruments Ltda. ${ }^{\circledR}$ ), antecipadamente calibrada em laboratório. A célula de carga foi instalada em um guincho agrícola, tracionado por um trator. Ao longo do trabalho, adotou-se a simplificação de considerar a força-peso (célula de carga) igual à massa (apontamento) $(9,81 \mathrm{~N}=1 \mathrm{kgf}=1 \mathrm{~kg})$.

Para verificar a relação entre os tratamentos, realizou-se o teste "t de Student" em análise pareada. Para a análise comparativa de erro dos apontadores das equipes, realizou-se o cálculo das diferenças entre o valor estimado e o valor real dos sacolões de cada turma.

A etapa de monitoramento da colheita de uma lavoura foi conduzida durante a mesma safra e consistiu no georreferenciamento de todos os sacolões de uma área específica e a obtenção dos dados de massa estimada pelo apontador. A quadra selecionada possui 15,89 ha, plantada com laranja "Valência" em espaçamento de 3,5 m entre plantas e 7,5 m entre as linhas de plantio. 
No georreferenciamento, foi utilizado um receptor de GPS AgGPS 132 (Trimble Navigation Limited $^{\circledR}$ ) conectado a um computador de mão, utilizando o programa de navegação Farm Site Mate (Farm Works Software ${ }^{\circledR}$ ). Para o apontamento de massa estimada, foi utilizada a técnica da régua graduada.

Para o cálculo da produtividade de cada sacolão, é necessária a obtenção da área de contribuição, conforme obtido por MOLIN et al. (2004) em cana-de-açúcar. Para tanto, as coordenadas geográficas foram convertidas para coordenadas métricas (UTM), permitindo o cálculo das distâncias entre os sacolões. A área de contribuição de um sacolão é compreendida pela metade da distância entre os pontos vizinhos, e a multiplicação desse comprimento com a largura da faixa de colheita, geralmente de $30 \mathrm{~m}$, equivale ao espaçamento entre linhas multiplicado pelo número de linhas que a frente de colheita trabalha: quatro linhas no presente caso.

Foi realizada a análise estatística e a geoestatística para o conjunto de dados da área utilizando o programa GS+ ${ }^{\circledR}$ (Geoestatistical for Environmental Sciences). A partir dos pontos de produtividade, foi feita a interpolação dos dados com grade de $10 \mathrm{~m}$ de lado, para a obtenção do mapa de produtividade, utilizando o SIG SSToolbox (SST Development Group ${ }^{\circledR}$ ). Tanto para o mapa de pontos quanto o interpolado, utilizou-se de três classes estabelecidas pelo critério de quartis, que procura distribuir a população de pontos em classes com o mesmo número de elementos.

\section{RESULTADOS E DISCUSSÃO}

\section{Caracterização dos sistemas de colheita}

As observações realizadas permitiram estabelecer que há um sistema predominante que segue descrito iniciando pela composição da equipe de colheita, também conhecida como "turma de colheita", que é definida pela capacidade do veículo de transporte utilizado e varia de 45 a 50 pessoas. A cada colhedor é atribuído um número de identificação e eles recebem o material necessário para o trabalho, como uma sacola, uma escada e alguns sacolões ("big bag") para armazenamento das frutas colhidas. O sacolão possui dimensões que variam de acordo com as necessidades da propriedade, com capacidade média de $600 \mathrm{~kg}$.

A equipe inicia a colheita e na rua central de cada faixa chamada de "bancada" ou "banca de colheita" são depositados os sacolões. Entre as empresas consultadas, a largura da faixa de colheita varia de quatro a seis plantas (Figura 1).
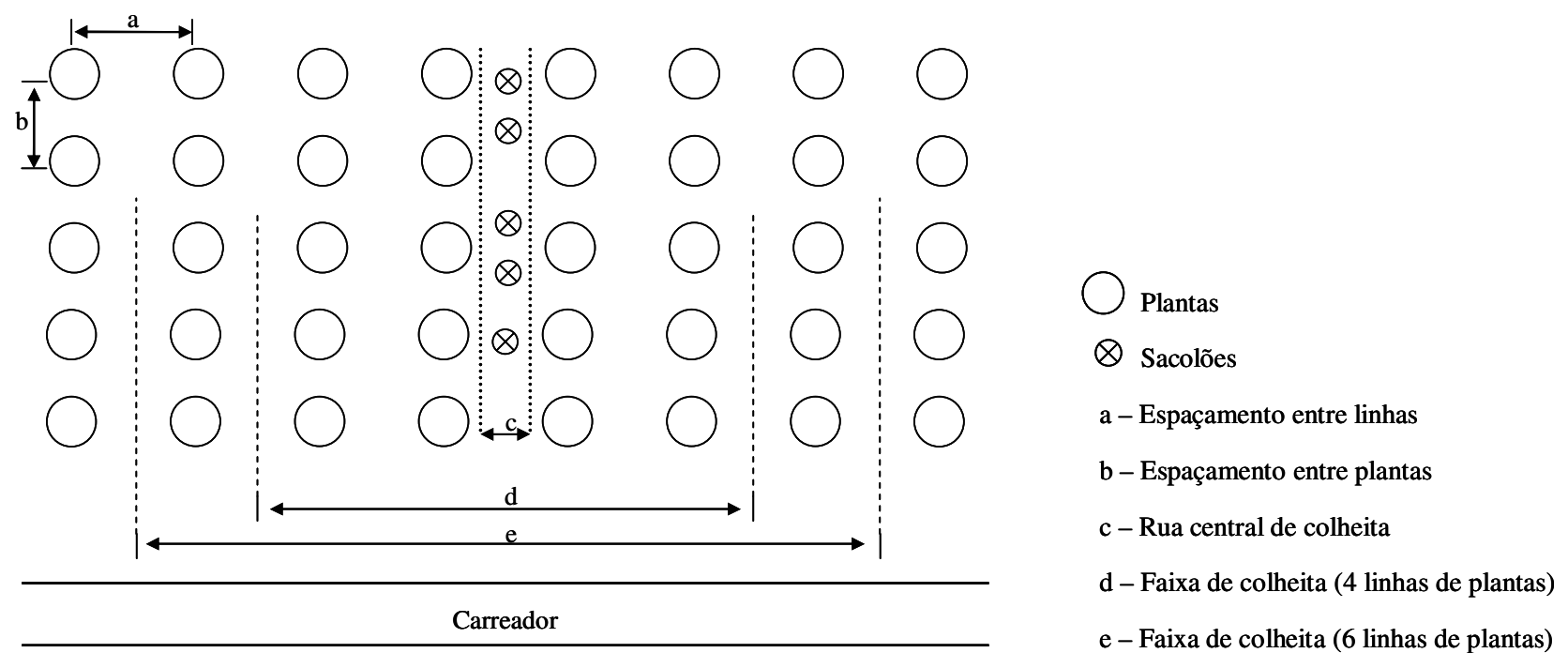

FIGURA 1. Esquema representando faixas de colheita de quatro e de seis linhas de plantas, adotadas nas propriedades citrícolas visitadas. 
O número de plantas na linha a serem colhidas por um colhedor é determinado pelo responsável, com base no conhecimento e no rendimento previsto de cada pessoa. As frutas são arrancadas e colocadas na sacola pendurada ao corpo do colhedor. Quando essa enche, o colhedor desloca-se até a rua central e utiliza a abertura inferior da sacola para descarregá-la no sacolão.

Acompanhando a equipe, existe um responsável, denominado de "empreiteiro", "turmeiro" ou "apontador". A ele cabe a fiscalização do processo de colheita, distribuição e organização dos colhedores e principalmente a realização do "apontamento" onde é determinada a quantidade de frutos que cada colhedor colheu na jornada. Antes da colheita, o apontador faz marcações em uma régua que é utilizada para medir a altura de frutos nos sacolões. A resolução do apontamento é de $27,2 \mathrm{~kg}$, devido à marcação na régua ser realizada pelo volume equivalente a uma caixa, obtendo assim valores múltiplos de uma caixa de colheita $(27,2 \mathrm{~kg})$, conhecida também como "caixinha".

$\mathrm{Na}$ operação de carregamento, existem algumas características diferenciadas entre as empresas citrícolas. Um sistema é composto por um trator com uma carreta basculante (aproximadamente $7 \mathrm{t}$ ), com um guindaste hidráulico acoplado. Esse conjunto transita pela rua central. Para que a abertura inferior do sacolão seja liberada sobre a carreta, o guindaste possui um gancho onde é engatada a alça de abertura, e a partir do trator o operador aciona um comando que ativa um cilindro hidráulico para a liberação das frutas. Quando a carreta está cheia, é direcionada ao carreador onde haverá um caminhão aguardando para receber a produção que é transportada até o silo de armazenamento ("bin"). Esse local possui capacidade variável de acordo com as necessidades da propriedade e é elevado do solo a uma altura superior à altura das carretas para que essas possam ser carregadas por gravidade para, então, levar as frutas para a indústria.

No momento da pesagem para a comercialização da produção ou para o controle de produção por parte da fazenda, as frutas são contabilizadas na forma de "caixa-peso" ou "caixa-padrão", que representa $40,8 \mathrm{~kg}$.

O outro sistema utiliza uma carregadora montada sobre um trator que transita na rua central de cada faixa. Em uma rua lateral, acompanhando a carregadora, transita um caminhão, onde é descarregada a produção contida nos sacolões, e esse a leva até o silo. O sistema utiliza dois caminhões para cada carregadora, permitindo que um receba o produto no campo enquanto o outro estará em processo de descarga.

\section{Aferição do apontamento}

Inicialmente, são apresentados os resultados obtidos com a mensuração dos pesos dos sacolões realizados com a célula de carga e as estimativas de massa feitas pelo apontador, referentes às duas equipes de colheita. Na Tabela 1, é apresentado o resumo estatístico descritivo desses dados.

TABELA 1. Estatística descritiva dos pesos dos sacolões de laranjas referentes às equipes de colheita.

\begin{tabular}{lcccc}
\hline & Massa $(\mathrm{kg})$ & Apontamento & Célula de Carga & Diferença \\
\hline \multirow{3}{*}{ Equipe 1 } & Média aritmética & $540,69 \mathrm{a}^{*}$ & $559,95 \mathrm{a}$ & $-19,25 \mathrm{~A}^{* *}$ \\
& C.V. $(\%)$ & 26,03 & 26,55 & \\
& Soma & 35.145 & 36.396 & $-1.251(3,42 \%)$ \\
\hline \multirow{3}{*}{ Equipe 2 } & Média aritmética & $560,15 \mathrm{a}$ & $582,87 \mathrm{a}$ & $-22,71 \mathrm{~A}$ \\
& C.V. $(\%)$ & 23,98 & 22,29 & \\
& Soma & 36.410 & 37.886 & $-1.476(3,89 \%)$ \\
\hline
\end{tabular}

*Médias seguidas de letras minúsculas iguais nas linhas representam diferença (95\%), pelo teste t-pareado

**Médias seguidas de letras maiúsculas iguais nas colunas não apresentam diferença (95\%), pelo teste $\mathrm{t}$

A diferença entre os tratamentos mostrou que, em média, a massa estimada pelo apontador da equipe 1 foi de $19,25 \mathrm{~kg}$ e da equipe 2 de 22,71 $\mathrm{kg}$ abaixo dos valores obtidos com a célula de carga para cada sacolão. No total da amostragem realizada, obteve-se diferença que representa 
$3,42 \%$ na equipe 1 e $3,89 \%$ na equipe 2 . As estimativas tendem a ser abaixo do real, chegando a valores extremos de $75,0 \mathrm{~kg}$ a menos para a equipe 1 e de $83,5 \mathrm{~kg}$ a menos para a equipe 2 . Observou-se que o apontador tende a estimar massa menor, para não se comprometer em determinar um valor acima do real, o que gera problemas no cálculo de quantidades colhidas e, conseqüentemente, nos pagamentos aos colhedores, sendo de sua responsabilidade os erros ocorridos e o reembolso dos valores discrepantes.

A ausência de diferença estatística dos valores médios de desvio da massa estimada em relação ao peso real indica que a boa qualidade do apontamento independe da pessoa que o realiza. No entanto, devem-se considerar apontadores que já possuam prática e que o processo de calibração envolvido na mensuração dos volumes dos sacolões seja realizado de forma correta.

Os desvios observados confirmam o padrão encontrado nas empresas citrícolas, segundo informações de seus responsáveis. Apesar de as análises indicarem diferença significativa entre as massas estimadas pelos apontadores e aquelas obtidas com a célula de carga, se for considerado que é um método prático e não-instrumental, pode ser considerado como aceitável. Além disso, observa-se que o erro é tendencioso e, portanto, pode ser minimizado com medidas gerenciais de orientação e calibração.

Outra forma de obter a informação de massa dos sacolões seria pela instalação de sensores de posição e célula de carga nas máquinas utilizadas no carregamento, conforme utilizado por BALASTREIRE et al. (2002). No início do projeto, foi testada a colocação da célula de carga na carregadora de sacolões utilizada pela empresa. Foram encontradas muitas dificuldades em relação à adaptação da carregadora para receber a célula de carga em função da posição e forma de fixação do cabeçote de ganchos à haste. $\mathrm{O}$ trabalho realizado pela carregadora é muito rápido e brusco, não permitindo a estabilização da carga para a leitura sem interferência, obtendo-se erros de leitura e comprometendo a informação. Por essas razões, optou-se por utilizar o guincho agrícola para pesagem da população de sacolões e determinar a confiabilidade da massa estimada pelo apontador.

Um sistema de pesagem instalado em carregadoras de cana-de-açúcar, semelhantes às utilizadas em laranja, foi testado por CUGNASCA et al. (2000) e obtiveram erros na ordem de $12 \%$ no valor obtido pela pesagem em relação ao valor real. No mesmo trabalho, utilizaram sensores para a correção dos erros, que ficaram na ordem de $2 \%$, e se fosse possível obter esse valor consistentemente, isso seria considerado uma melhoria significativa. Porém, sob certas condições de teste, a forma de operação da máquina introduziu perturbações, com erros de até $10 \%$, que afetaram o desempenho do sistema. Considerando que os erros encontrados nos valores estimados pelo apontador são menores, pode-se concluir que a informação obtida pelo apontador é mais confiável e precisa do que outras formas de obtenção de massa dos sacolões que poderiam acarretar em um conjunto de erros que seriam maiores e a um custo e complexidade mais elevados. Para que a massa estimada pelo apontador seja sempre a mais próxima possível da real, deve-se realizar calibração criteriosa do método da régua graduada, utilizada na determinação de quantidade de produção contida em um sacolão. Essa calibração deve ser repetida no momento de mudança de área, onde se tem variação de tamanho e peso do fruto devido a variações climáticas ou tipo de cultivares.

\section{Mapeamento da produtividade}

Primeiramente, foram obtidos os pontos georreferenciados e os valores de massa estimados pelo apontador, realizados para cada sacolão. Dessa forma, gerou-se uma tabela com as coordenadas (latitude e longitude) e o número de caixas de colheita $(27,2 \mathrm{~kg}$ ) apontadas em cada sacolão, que foram transformados em massa $(\mathrm{kg})$. Foram coletados 683 pontos, divididos em 30 faixas de colheita, dentro da área. Esses foram plotados no SIG para visualização, e calculada a produtividade individual dos pontos. 
A metodologia utilizada para realizar o cálculo de produtividade demonstrou que pode ser facilmente implementada em áreas comerciais de citros, ou mesmo ser adaptada para qualquer outra cultura que utilize o sistema de colheita manual e onde as células apresentam largura fixa.

A distribuição de frequiência do conjunto de dados de produtividade pode ser visualizada no histograma apresentado na Figura 2. Além da descrição gráfica, foi gerada a estatística descritiva dos dados de produtividade equivalentes a cada sacolão, obtendo-se a média de $25,28 \mathrm{t} \mathrm{ha}^{-1} \mathrm{e}$ elevado coeficiente de variação $(56,9 \%)$. Os valores de produtividade variaram entre 1,54 e $101,08 \mathrm{t} \mathrm{ha}^{-1}$.

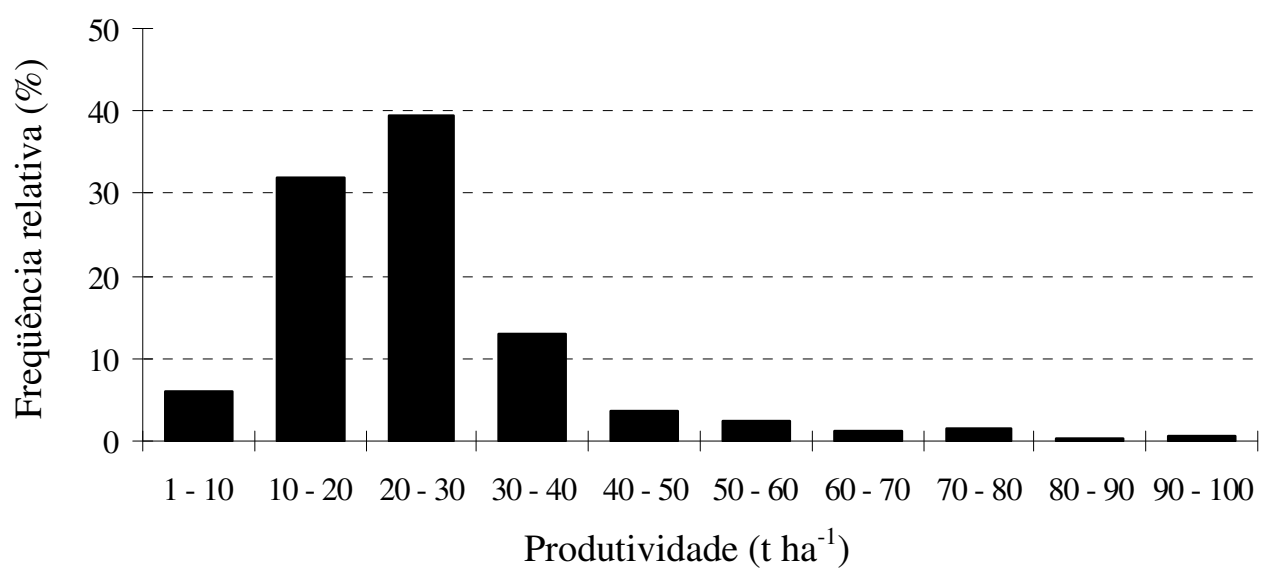

FIGURA 2. Histograma dos dados de produtividade das áreas associadas a cada sacolão.

Observam-se poucos valores de produtividade acima de $60 \mathrm{tha}^{-1}$ que, de acordo com a propriedade, é o valor máximo de produtividade média encontrada nos diferentes anos de colheita. Esses valores extremos são referentes a sacolões localizados muito próximos de seus vizinhos, justamente demonstrando que são regiões de elevada produção. Na Figura 3, é apresentado o mapa que representa a posição de cada sacolão e a produtividade a eles associada, com três classes estabelecidas pelo critério de quartis. Esse mapa indica que áreas com maior densidade de pontos são regiões de alta produtividade, já regiões onde os pontos estão mais espaçados, representam baixa produtividade. WHITNEY et al. (2001) e SCHUELLER et al. (1999), georreferenciando recipientes em colheita manual, também encontraram regiões de alta produtividade representadas justamente por maior densidade de pontos.

De acordo com os valores contabilizados na propriedade, a produtividade média obtida na área de estudo foi de 22,80 tha ${ }^{-1}$. No entanto, a fazenda não cumpre a rigor o controle de transporte individual para cada talhão. No caso do talhão experimental, reportaram que houve transposição de alguns sacolões para complementação de carga do caminhão que retirava a produção de outro talhão, sem que se tivesse controle absoluto sobre esse valor, o que acarreta incerteza no julgamento da totalização informada. Essa produtividade é considerada baixa em relação aos registros de dados históricos anuais da propriedade.

$\mathrm{Na}$ análise geoestatística dos dados de toda a população de pontos da lavoura, obteve-se o semivariograma que caracterizou "efeito pepita puro". Da mesma forma, optou-se por realizar essa análise para cada linha de pontos, referente às faixas de colheita, resultando novamente em "efeito pepita puro" em todos os casos. Esse fato pode ter sido causado pala ocorrência de pontos de alta produtividade muito próximos de alguns pontos com baixa produtividade, motivados justamente pela presença de sacolões extras, não-cheios, em locais de alta produtividade. Isso indica que o método tem limitação de resolução, não sendo capaz de captar variabilidades locais, devido à própria limitação de acurácia de posicionamentos dos sacolões, tanto por conta do colhedor que pode posicioná-lo próximo de um outro, como pelo sistema de posicionamento utilizado (GPS) para georreferenciar os sacolões. Devido a isso, optou-se por utilizar o "inverso do quadrado da distância", como sugerido por MOORE (1998), como interpolador para a geração da superfície que representa o mapa de produtividade (Figura 3). As três classes foram novamente estabelecidas 
pelo critério de quartis. Observa-se que os valores extremos presentes nos pontos foram suavizados após a interpolação.

(a)

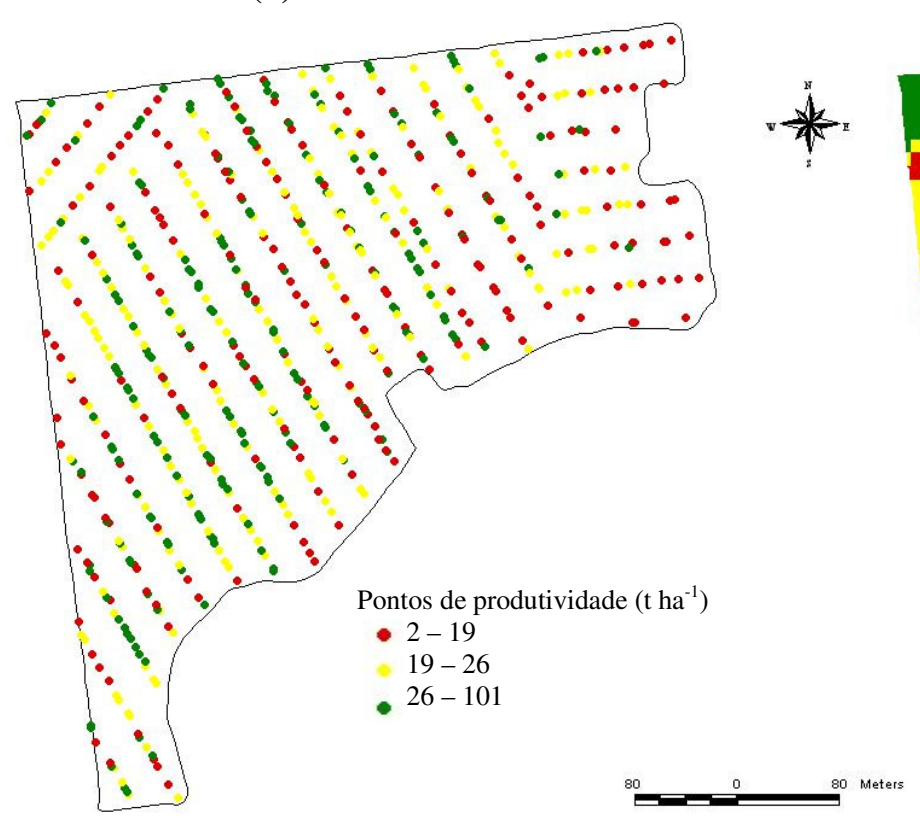

(b)

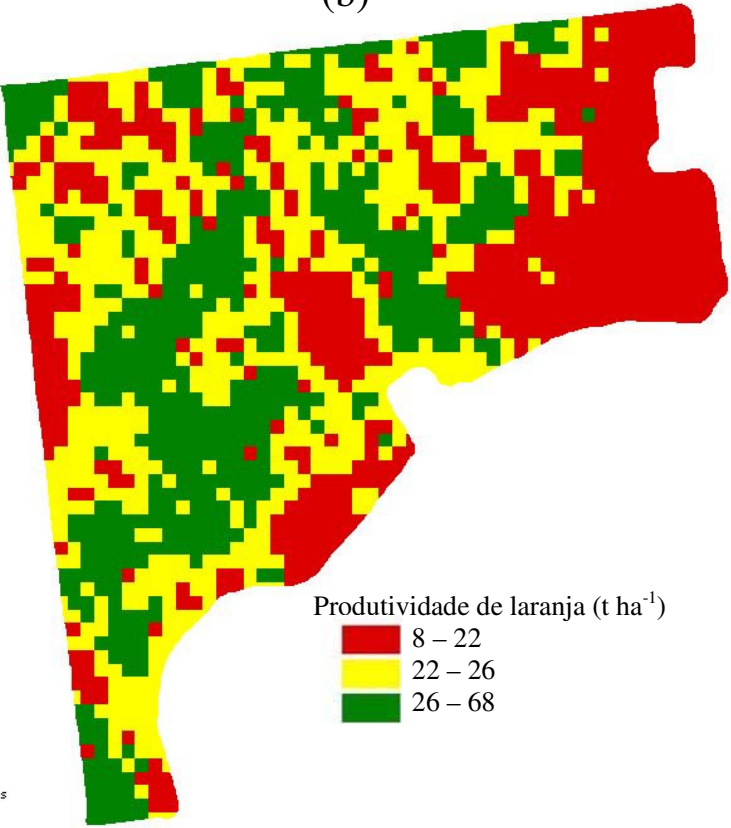

FIGURA 3. Mapa representando a posição de cada sacolão na lavoura e a produtividade a ele associada (a) e mapa representando a superfície da produtividade de laranja (b).

A partir do mapa de produtividade, pode-se observar a sensível variabilidade espacial da produção de laranja na área, identificando regiões de alta e baixa produtividades. Algumas regiões do mapa, principalmente a nordeste, apresentam valores abaixo de $22 \mathrm{t} \mathrm{ha}^{-1}$, que é considerado pela propriedade como sendo a menor produtividade média histórica, devendo as causas serem investigadas para possíveis intervenções localizadas. Também observam-se áreas de alta produtividade, ambas em agrupamentos distribuídos ao centro da área, indicando que existe variabilidade espacial da produção. A determinação de regiões diferenciadas dentro da área, obtidas a partir dos mapas de produtividade, é a forma de identificar e posteriormente investigar as causas dessas variabilidades. Esse comportamento na produtividade de lavouras de citros também foi observado por WHITNEY et al. (1998) e SCHUELLER et al. (1999). FARIAS et al. (2003) encontraram variabilidade na produtividade de uma área não-irrigada, onde as maiores produtividades se localizavam próximas a um córrego com maior umidade do solo, mas a irrigação provavelmente não foi o único fator, podendo a produtividade ter sido influenciada pelo tipo de solo, fertilidade e pragas, entre outros.

\section{CONCLUSÕES}

Os sistemas de colheita de citros caracterizados apresentam algumas diferenciações adaptadas às condições de cada empresa. A técnica de determinação do volume de frutas no sacolão, com régua graduada, é utilizada por todas as empresas consultadas como forma de determinar o pagamento dos colhedores, sendo essa estimativa obtida pelo apontador considerada aceitável para a estimativa de produtividade por ser simples e de baixo custo.

A metodologia utilizada para realizar o cálculo de produtividade demonstrou que pode ser facilmente implementada. O método mostrou-se válido para a coleta de dados e a geração do mapa de produtividades, podendo-se observar a variabilidade espacial dentro da quadra. 


\section{AGRADECIMENTOS}

À empresa Citrosuco Paulista (Fischer), pela disponibilidade da área e pela colaboração de seus funcionários (Fazenda Santa Isabel) no projeto.

\section{REFERÊNCIAS}

BALASTREIRE, L.A.; AMARAL, J.R.; ESQUERDO, J.C.D.M. Agricultura de precisão: mapeamento da produtividade de uma cultura de laranja. In: BALASTREIRE, L.A. Avanços na agricultura de precisão no Brasil no período de 1999-2001. Piracicaba: ESALQ/LER, 2002. cap. 2, p. 151-7.

CUGNASCA, C.E.; HIRAKAWA, A.R.; SARAIVA, A.M.; SANTANA, J.I.; PIEROSSI, M.A.; HASSUANI, S.J. Pesagem dinâmica em carregadoras de cana-de-açúcar para elaboração de mapas de colheita. In: BALASTREIRE, L.A. (Org.). O Estado-da-arte da agricultura de precisão no Brasil. Piracicaba: O Autor, 2000. p.129-35.

FAO. FAOSTAT data 2005. Disponível em: <http:/faostat.fao.org/>. Acesso em: 15 jun. 2005.

FARIAS, P.R.S.; NOCITI, L.A.S.; BARBOSA, J.C.; PERECIN, D. Agricultura de precisão: mapeamento da produtividade em pomares cítricos usando geoestatística. Revista Brasileira de Fruticultura, Jaboticabal, v.25, n.2, p.235-41, 2003.

HORROM, N. Citrus yield monitoring and mapping. In: INTERNATIONAL SOCIETY OF CITRICULTURE CONGRESS, 2000, Orlando. Proceedings... Orlando: ISC, 2000. p.219.

MILLER, W.M.; WHITNEY, J.D. Development of yield monitoring systems for Florida citrus. ASAE ANNUAL INTERNATIONAL MEETING, 1998, Orlando. Proceedings... St. Joseph: ASAE, 1998. 12 p. (Paper, 981098).

MOLIN, J.P.; FONTANA, G.; GUIMARÃES, R.V.; CABRERA, F.R.; COSTA, M.B. Elaboração de mapas de produtividade de cana-de-açúcar em corte manual com queima prévia. In:

CONGRESSO BRASILEIRO DE AGRICULTURA DE PRECISÃO, 2004, Piracicaba. Anais... Piracicaba: ESALQ, 2004. 1 CD-ROM.

MOORE, M. An investigation into the accuracy of yield maps and their subsequent use in crop management. 1998. 379 f. Tese (Doutorado em Engenharia Agrícola) - Cranfield University, Cranfield, 1998.

PARISE, F.J.O. Padrões de variabilidade espacial e temporal da produção em um pomar jovem de laranja Hamlin. 2004. 107 f. Tese (Doutorado em Irrigação e Drenagem) - Escola Superior de Agricultura "Luiz de Queiroz", Universidade de São Paulo, Piracicaba, 2004.

SCHUELLER, J.K.; WHITNEY, J.D.; WHEATON, T.A.; MILLER, W.M.; TURNER, A.E. Lowcost automatic yield mapping in hand-harvested citrus. Computers and Electronics in Agriculture, New York, v.23, n.2, p.145-53, 1999.

WHITNEY, J.D.; LING, Q.; WHEATON, T.A.; MILLER, W.M. A citrus harvesting labor tracking and yield mapping system. Applied Engineering in Agriculture, St. Joseph, v.17, n.2, p.121-5, 2001.

WHITNEY, J.D.; MILLER, W.M.; WHEATON, T.A.; SALYANI, M. Precision farming applications in Florida Citrus. In: ASAE ANNUAL INTERNATIONAL MEETING, 1998, Orlando. Proceedings... St. Joseph: ASAE, 1998. 10 p. (Paper, 981097). 